\title{
Sea buckthorn pomace supplementation in the finishing diets of pigs - are there effects on meat quality and muscle fatty acids?
}

\author{
K. Nuernberg ${ }^{1}$, G. Nuernberg ${ }^{2}$, A. Priepke ${ }^{3}$, and D. Dannenberger ${ }^{1}$ \\ ${ }^{1}$ Institute of Muscle Biology and Growth, Leibniz Institute for Farm Animal Biology (FBN), \\ Dummerstorf, Germany \\ ${ }^{2}$ Institute of Genetics and Biometry, Leibniz Institute for Farm Animal Biology (FBN), Dummerstorf, Germany \\ ${ }^{3}$ Institute of Animal Production, State Institute for Agriculture and Fishing Research (LFA), \\ Dummerstorf, Germany
}

Correspondence to: D. Dannenberger (dannenberger@fbn-dummerstorf.de)

Received: 23 October 2014 - Accepted: 9 February 2015 - Published: 18 March 2015

\begin{abstract}
In the present study, the effect of sea buckthorn pomace (SBP) supplementation (concentrations of 0 , 4,8 and $12 \%$; intervention duration of 4 or 8 weeks) on finishing performance, meat quality parameters, and fatty acid and vitamin C contents in muscle of German Landrace pigs was assessed. Supplementation with SBP did not negatively affect growth performance and slaughter quality traits of pigs. The overall meat quality including nutrient composition (protein, fat, water), meat colour and $\mathrm{pH}$ value was not changed. Surprisingly, the fatty acid profile of longissimus muscle was only slightly affected by different SBP concentrations and intervention durations. Highest amounts of $n-3$ fatty acids $(28 \mathrm{mg} / 100 \mathrm{~g}$ muscle) were measured in pig muscle which had received a $12 \%$ SBP-supplemented ratio with over an intervention period of 8 weeks. The contents for vitamin $\mathrm{C}$ of longissimus muscle of pigs of the control group and SBP supplementation groups varied between 24.0 and $28.7 \mu \mathrm{g} \mathrm{g}^{-1}$ fresh muscle, and were not diet affected. Other diet compositions and possibly changes in SBP during the manufacturing process of diet pellets should be included in investigations to develop an application-oriented concept of SBP as a supplement for pig feeding.
\end{abstract}

\section{Introduction}

The quality of meat/meat products is of crucial relevance for researchers, producers and consumers. Considerable attention has been paid to improvements in the nutritional value of meat and the development of products beneficial for human health and disease prevention. Consumers are becoming increasingly interested in safe, tasty, healthy and regional-origin meat products produced under eco-friendly, animal-friendly and sustainable (resource-conserving) conditions. The fat quality of pork can be positively affected by supplementation of animal diets with different oilseeds and oilseed press cakes (e.g. linseed, rapeseed products) as well as grass (Nuernberg et al., 1998, 2011; Vaclavkova and Beckove, 2007; Dannenberger et al., 2012; Morel et al., 2013; Turner et al., 2014). Sea buckthorn is an indigenous culti- var found between the Atlantic coast of Europe and northwestern Mongolia and China. In the north-eastern part of Germany (Mecklenburg-Western Pomerania) sea buckthorn represents a natural rank-growing coastal protection, and is grown on plantations of approximately 150 ha (Hornig and Hoehne, 2011). Many sea buckthorn products (juices, teas, liqueur, jams, personal care products, etc.) are on the market as niche products. During processing of sea buckthorn berries, high-quality press cakes (pomace) are generated as by-products. These residues of juice or oil production contain high amounts of valuable vitamins, flavonoids and special fatty acids, although there are high variations depending on season or cultivar (Cossuta et al., 2007). The nutritional value of sea buckthorn (Hippophae rhamnoides L.) and its pharmacological effects result from the chemical composition. High amounts of different vitamins (vitamin C, vita- 
min $\mathrm{E}$, and carotenoids like $\beta$-carotene and lycopene $\mathrm{B} 2$ ) and secondary plant metabolites like flavonoids (Kagliwal et al., 2012) are abundant in fruit pulp and seeds. It is well known that sea buckthorn has excellent antioxidant properties because of these bioactive substances (Korekar et al., 2011). Therefore, sea buckthorn extracts are applied in the prevention of flu and cough, in burn therapy, and to support wound healing and stimulate the immune and cardiovascular system. Sea buckthorn berries and leaves have been primarily used in traditional Asian medicine. Most extensive scientific research concerning health effects of sea buckthorn and leaf extracts has been conducted in central Asia (Prabhu, 2011). The lipid fraction of sea buckthorn contains on average 6$13 \% \alpha$-linolenic acid (C18:3n-3, ALA) and has a low ratio of $n-6 / n-3$ polyunsaturated fatty acids (PUFA) of 1.1-1.3 and a high concentration of monounsaturated fatty acids (49$52 \%$, MUFA). Recent studies have reported that the exogenous intake of oleic acid (C18:1cis-9) can induce lowered blood fat, improved HDL to LDL cholesterol ratios and inhibition of inflammatory processes in blood vessels (Pfeuffer, 2001; Lopez et al., 2012; Baum et al., 2012; Miura et al., 2013).

To our best knowledge, the effects of dried sea buckthorn pomace (SBP) supplementation on growth and meat/fat quality in finishing pigs have only been reported in the study of Zhang et al. (2009). The focus of the present study was the investigation of the effects of SBP supplementation in the finishing period of German Landrace pigs on growth characteristics, meat quality and fatty acid profiling of longissimus muscle.

\section{Material and methods}

\subsection{Experimental design}

In this study, in total 58 German Landrace castrates were (from two half-sib groups) kept at the experimental station of the Leibniz Institute for Farm Animal Biology in Dummerstorf from September to November 2013. The pigs were randomly assigned into six feeding groups at a live weight of $28 \mathrm{~kg}$ ( 9 to 10 pigs per pen). Pigs were fed diets supplemented with different concentrations of dried SBP over two different intervention durations - control group (CG), $0 \%$ SBP; feeding group 1 (FG1), $4 \%$ SBP over 8 weeks; feeding group 2 (FG2), $8 \%$ SBP over 4 weeks; feeding group 3 (FG3), $8 \%$ over 8 weeks; feeding group 4 (FG4), $12 \%$ for 4 weeks; and feeding group 5 (FG5), $12 \%$ over 8 weeks (see Table 2). Animal keeping and feeding were in accordance with animal care regulations (no. 7221.3-2.1-019/13). The individual feed intake was registered daily via a transponder and the weight development of the animals was measured weekly. The composition of the diets of the four basic diet mixtures $(0,4,8,12 \% \mathrm{SBP})$ was isoenergetically and isonitrogenously balanced. The diet components, nutrient composition and fatty acid profile of dried sea buckthorn
Table 1. Nutrient and fatty acid composition of dried sea buckthorn pomace (SBP).

\begin{tabular}{|c|c|}
\hline & $\begin{array}{l}\text { Sea buckthorn pomace } \\
\text { (SBP), dried }\end{array}$ \\
\hline \multicolumn{2}{|l|}{ Nutrient composition } \\
\hline Dry matter $(\%)$ & 87.7 \\
\hline Crude fat $(\%)$ & 14.5 \\
\hline Crude protein $(\%)$ & 14.6 \\
\hline Crude fibre $(\%)$ & 23.0 \\
\hline Sugar $(\%)$ & 0.2 \\
\hline $\operatorname{Starch}(\%)$ & 5.7 \\
\hline Neutral detergent fibre (NDF, \%) & 39.7 \\
\hline Acid detergent fibre $\quad(\mathrm{ADF}, \%)$ & 36.2 \\
\hline Energy (MJ) & 13.1 \\
\hline \multicolumn{2}{|l|}{ Fatty acid profile (\%) } \\
\hline $\mathrm{C} 14: 0$ & 0.2 \\
\hline $\mathrm{C} 16: 0$ & 24.8 \\
\hline C16: 1 & 20.4 \\
\hline C18:0 & 1.3 \\
\hline C18: 1cis-9 & 19.3 \\
\hline $\mathrm{C} 18: 2 n-6$ & 11.6 \\
\hline $\mathrm{C} 18: 3 n-3$ & 9.7 \\
\hline$N-6 / n-3$ PUFA ratio & 1.2 \\
\hline
\end{tabular}

Table 2. Experimental design.

\begin{tabular}{lrrrrrr}
\hline & CG & FG1 & FG2 & FG3 & FG4 & FG5 \\
\hline Pomace proportion (\%) & 0 & 4 & 8 & 8 & 12 & 12 \\
$\begin{array}{l}\text { Animal number } \\
\text { Duration of application }\end{array}$ & 8 & 9 & 10 & 9 & 10 & 10 \\
(week) & 8 & 4 & 8 & 4 & 8 \\
\hline
\end{tabular}

pomace and the four basic diet mixtures are shown in Tables 1 and 3. All experiments were conducted simultaneously to avoid seasonal effects between the different feeding groups. All diet composition components were analysed before the beginning of the experiment as a basis for the final diet calculations. Pigs were slaughtered within 2 weeks after a 4-week (FG2 and FG4) or 8-week (CG, FG1, FG3, FG5) diet intervention at the abattoir of the Leibniz Institute for Farm Animal Biology in Dummerstorf (Germany) according to the EU regulations. The slaughter and dressing procedures were performed in accordance with EU specifications. Immediately after slaughtering, tissue samples were collected from the right side of the carcass. Longissimus muscles used for the analysis of meat quality and fatty acid concentrations were taken from the $13 \mathrm{th} / 14$ th rib and stored at $-80^{\circ} \mathrm{C}$ until analysis. Longissimus muscle samples (11th/12th rib) were removed immediately after slaughter, shredded with an IKA M 20 mill (IKA Werke, Staufen, Germany) under liquid nitrogen and stored at $-70^{\circ} \mathrm{C}$ until preparation for vitamin $\mathrm{C}$ analyses. 
Table 3. Feed components, chemical and fatty acid composition of the rations.

\begin{tabular}{lrrrr}
\hline & CG & $4 \%$ SBP & $8 \%$ SBP & $12 \%$ SBP \\
\hline Feed components (\%) & & & & \\
\hline SBP & - & 4.0 & 8.0 & 12.0 \\
Wheat & 26.2 & 24.3 & 55.5 & 53.4 \\
Barley & 20.0 & 20.0 & 5.0 & - \\
Triticale & 20.0 & 20.0 & - & - \\
Rye & 15.0 & 15.0 & 15.0 & 15.0 \\
Soybean meal & 11.8 & 12.0 & 11.3 & 12.5 \\
Soybean skin & 2.5 & & & \\
Beet molasses & 0.75 & 1.0 & 1.0 & \\
Dextrose & & & 0.43 & 3.3 \\
\hline Nutrient composition & & & & \\
\hline Crude fat (\%) & 2.7 & 3.2 & 3.4 & 3.6 \\
Crude protein (\%) & 15.4 & 16.1 & 15.9 & 15.6 \\
Energy (MJ) & 13.4 & 13.5 & 13.4 & 12.2 \\
Lysine (\%) & 0.68 & 0.69 & 0.66 & 0.60 \\
\hline Fatty acid profile (\%) & & & & \\
\hline C14:0 & 0.43 & 0.44 & 0.47 & 0.45 \\
C16:0 & 20.5 & 20.8 & 21.3 & 21.5 \\
C16: 1 & 1.2 & 2.6 & 3.7 & 5.0 \\
C18:0 & 2.4 & 2.4 & 2.4 & 2.3 \\
C18: 1 cis-9 & 17.5 & 18.2 & 19.1 & 19.5 \\
C18: $n$-6 & 47.4 & 44.6 & 41.8 & 39.4 \\
C18: $n$-3 & 5.8 & 5.8 & 5.6 & 5.8 \\
\hline
\end{tabular}

\subsection{Carcass performance and meat quality}

The measurements of parameters of finishing and slaughter performance and meat quality were conducted in accordance with recent national legislation ("Richtlinie für die Stationsprüfung auf Mastleistung, Schlachtkörperwert und Fleischbeschaffenheit beim Schwein; Zentralverband der deutschen Schweinproduktion", 2007). The classification of the carcasses were conducted with a FAT-o-Meater S89, (Carometec, Soeborg, Denmark). To characterise the fat incorporation, backfat thickness $(\mathrm{cm})$, intramuscular fat content (FoodScan ${ }^{\mathrm{TM}}$ Lab, FOSS, Denmark) and fatty acid profile of M. longissimus dorsi were assessed. The $\mathrm{pH}$ values of muscle tissue were measured $45 \mathrm{~min}$ and $24 \mathrm{~h}$ post-mortem with a pH-Star CPU (Matthaeus, Nobitz, Germany) in the left half of carcass at the 13th/14th rib. Meat colour $\left(\mathrm{L}^{*}\right)$ of muscle and backfat was analysed after $24 \mathrm{~h}$ in refrigerated storage with a Minolta CR 300 (Minolta GmbH, Ahrensburg, Germany) with three replicates at the fresh cutting area. Drip loss of $50 \mathrm{~g}$ muscle tissue was determined after $24 \mathrm{~h}$ refrigerated storage in resealable plastic bags. The details of meat quality parameter determination are described in Dannenberger et al. (2012).

\subsection{Fatty acid analysis}

Longissimus muscle samples (11th/12th rib) were removed immediately after slaughter, shredded with an IKA M20 mill (IKA Werke, Staufen, Germany) under liquid nitrogen and stored at $-70^{\circ} \mathrm{C}$ until preparation for lipid analyses. Two grams of muscle powder was thawed at $4{ }^{\circ} \mathrm{C}$, and the total lipids were extracted in duplicate with chloroform / methanol $(2: 1, v / v)$ by using an Ultra Turrax homogeniser $\left(3 \times 15 \mathrm{~s}, 12000 \mathrm{U} \mathrm{min}^{-1}\right.$; IKA Werke, Staufen, Germany) at room temperature as recently described in detail by Nuernberg et al. (2011). Briefly, the final lipid extracts were redissolved in $300 \mu \mathrm{L}$ of toluene, and a $25 \mathrm{mg}$ aliquot was used for methyl ester preparation. Sodium methoxide in methanol was added to the samples, which were shaken in a $60^{\circ} \mathrm{C}$ water bath for $10 \mathrm{~min}$. Subsequently, $1 \mathrm{~mL}$ of $14 \%$ boron trifluoride $\left(\mathrm{BF}_{3}\right)$ in methanol was added to the mixture, which was then shaken for an additional $10 \mathrm{~min}$ at $60^{\circ} \mathrm{C}$. Finally, the fatty acid methyl esters (FAME) were resuspended in $100 \mu \mathrm{L}$ of $n$-hexane and stored at $-18^{\circ} \mathrm{C}$ until use for gas chromatography (GC) analysis. The fatty acid analysis of the muscle lipids was performed using capillary GC with a CP-Sil $88 \mathrm{CB}$ column $(100 \mathrm{~m} \times 0.25 \mathrm{~mm}$, Chrompack-Varian, Lake Forest, CA, USA) that was installed in a PerkinElmer gas chromatograph Clarus 680 with a flame ionisation detector (PerkinElmer Instruments, Shelton, CT, USA). Detailed GC conditions are described in Shen et al. (2011). Hydrogen was used as the carrier gas at a flow rate of $1 \mathrm{~mL} \mathrm{~min}^{-1}$. The split ratio was $1: 20$, and the injector and detector were set at 260 and $280^{\circ} \mathrm{C}$, respectively.

\subsection{Vitamin $\mathrm{C}$ analysis}

Powered muscle $(1.5 \mathrm{~g})$, created following the same procedure as above, was homogenised with $2 \mathrm{~mL}$ of $60 \%$ methanol/1 $\mathrm{mM}$ ethylenediaminetetraacetic acid solution and $0.5 \mathrm{~mL}$ of $1.5 \%$ meta-phosphoric acid solution. After $15 \mathrm{~min}$ of centrifugation $\left(12000 \mathrm{Umin}^{-1}\right)$ the upper phase was cleaned by ultrafiltration with a VIVASPIN 500 (Sartorius, Göttingen, Germany). An isocratic RP-HPLC method was used for the identification and quantification of watersoluble vitamin $\mathrm{C}$ in pig muscle. All samples were analysed using an HPLC system (Shimadzu LC-10AD, Japan) equipped with a Shimadzu SIL-10A automatic injector, a Shimadzu SPD-10AV UV-VIS spectrophotometric detector. For the HPLC separation a $250 \times 40 \mathrm{~mm}$ Synergi ODS (Phenomenex, USA) HPLC column was used. The mobile phase was $20 \mathrm{mM}$ potassium dihydrogen orthophosphate and $0.015 \%$ meta-phosphoric acid ( $\mathrm{pH}$ value to 2.55 ). The total flow was $0.8 \mathrm{~mL} \mathrm{~min}^{-1}$ and runtime for vitamin $\mathrm{C}$ analysis was $15 \mathrm{~min}$. The UV detection was carried out at $243 \mathrm{~nm}$. For quantitative evaluation the external standard ascorbic acid (vitamin C) calibrated in the range between 8 and $143 \mu \mathrm{g} \mathrm{mL}-1$ was used. Analyses of muscle samples were carried out in duplicate. 
Table 4. Growth performance, carcass traits and meat quality of pigs fed diets supplemented with sea buckthorn pomace.

\begin{tabular}{llllllll}
\hline & CG & FG1 & FG2 & FG3 & FG4 & FG5 & \\
& LSM & LSM & LSM & LSM & LSM & LSM & SEM \\
\hline Age (d) & 171.3 & 170.6 & 170.3 & 169.8 & 171.1 & 171.1 & 1.2 \\
Final weight (kg) & 123.4 & 129.7 & 129.1 & 125.5 & 123.8 & 127.7 & 2.4 \\
ADG (g) & 982.8 & 1048.0 & 1014.5 & 1021.9 & 931.9 & 1026.6 & 32.0 \\
ADFI (kg) & $3.4^{\mathrm{ac}}$ & $3.7^{\mathrm{c}}$ & $3.8^{\mathrm{bc}}$ & $3.9^{\mathrm{bc}}$ & $3.4^{\mathrm{a}}$ & $3.5^{\mathrm{ac}}$ & 0.08 \\
LMP (\%) & 52.0 & 51.7 & 49.7 & 52.0 & 52.4 & 51.5 & 0.8 \\
Carcass weight hot (kg) & 99.4 & 104.5 & 104.4 & 103.6 & 98.5 & 101.6 & 1.8 \\
Back fat thickness (cm) & 2.7 & 2.7 & 2.9 & 2.8 & 2.7 & 2.9 & 0.1 \\
Liver (g) & $1928^{\mathrm{b}}$ & $2135^{\mathrm{a}}$ & $1959^{\mathrm{b}}$ & $1848^{\mathrm{b}}$ & $2105^{\mathrm{a}}$ & $2002^{\mathrm{b}}$ & 59.0 \\
\hline M. longissimus & & & & & & & \\
\hline Muscle area (cm $\left.{ }^{2}\right)$ & 49.4 & 47.9 & 48.4 & 49.1 & 47.4 & 49.5 & 1.3 \\
IMF (\%) & 1.5 & 1.4 & 1.6 & 1.5 & 1.6 & 1.6 & 0.1 \\
pH value 45 min & 6.4 & 6.4 & 6.4 & 6.4 & 6.4 & 6.4 & 0.05 \\
Meat colour L & 48.4 & 47.6 & 47.2 & 46.6 & 48.8 & 48.4 & 0.6 \\
Drip loss (\%) & 4.6 & 4.7 & 6.0 & 4.0 & 4.9 & 4.9 & 0.6 \\
\hline
\end{tabular}

a, b- significant differences at $P \leq 0.05$. ADG, average daily gain $\left(\mathrm{g} \mathrm{d}^{-1}\right)$ from 117 th day of life to slaughter; ADFI, average daily feed intake $\left(\mathrm{kg} \mathrm{d}^{-1}\right)$ from 117th $\mathrm{d}$ to slaughter; MFA, lean meat (\%) Auto-FOM.

\subsection{Statistical analysis}

The statistical analyses were performed by using the $\mathrm{SAS}^{\odot}$ software package $(9.4,2012)$. Since the animals were slaughtered at two time points within 2 weeks, a factor slaughter group $(1,2)$ was built. Because all 58 animals belong to two half-sib groups, both a fixed factor (father $(1,2)$ ) and a random factor ("mother within father") modelling the dependency of a full-sibs effect are used in the ANOVA model. All data were calculated via multifactorial variance analysis with the fixed factors feeding group (6 levels), father (1, $2)$, slaughter group $(1,2)$, corresponding interactions and the random factor "mother within father" by using the SAS procedure "mixed". In Tables 3 and 4, least-squares means (LSMs) and standard errors of the mean (SEM) of the investigated parameters are presented. For multiple comparison adjustment we used the Tukey-Kramer correction.

\section{Results}

The chemical and nutritional composition of the different rations is shown in Tables 1 and 3. All rations were isoenergetically and isonitrogenously calculated. The supplementation of pig rations with 4,8 or $12 \%$ SBP during the finishing period (4 or 8 weeks before slaughter) only slightly affected growth characteristics, carcass traits and meat quality (Table 4). The average daily gain (ADG) during the feeding period was not affected by diet. Intervention groups FG2 and FG3 had a significantly higher daily feed intake (ADFI) during the feeding period than the control group (CG). The lowest ADFI within the feeding groups was calculated for FG4. Liver mass $(\mathrm{kg})$ was significantly higher in FG1 and lower in FG3 pigs. Pigs were slaughtered at 169-171 days of life. The life weights ranged between 123 (CG) and $130 \mathrm{~kg}$ (FG1), while the daily gain during the feeding period varied between 932 (FG4) and $1048 \mathrm{~g}$ (FG1). Meat quality traits were not altered by concentration or by duration of the SBP intervention. The fatty acid profile in longissimus muscle is presented in Table 5. In addition, the concentration $(\mathrm{mg} / 100 \mathrm{~g})$ of ALA and the sum of $n-3$ fatty acids are shown (Fig. 1). Feeding rations supplemented with 4,8 and $12 \%$ SBP over 8 weeks induced a significant accumulation of ALA (\%, $\mathrm{mg} / 100 \mathrm{~g}$ ) compared with the control group (Table 5; Fig. 1). The $n-6 / n-3$ PUFA ratio was significantly lower in FG1, FG3 and FG5 compared with the control group (Fig. 1). The highest proportion of $\mathrm{C} 20: 3 n-6$ was measured in CG, FG1 and FG3, and the lowest in FG2 and FG5. The proportions of single and sum saturated fatty acids (SFA) were not affected by diet. Also, except for $\mathrm{C} 14: 1$, the monounsaturated fatty acids (MUFA) showed no diet effect (Table 5). The contents for vitamin $\mathrm{C}$ of longissimus muscle of pigs of the control group and SBP supplementation groups varied between 24.0 and $28.7 \mu \mathrm{g} \mathrm{g}^{-1}$ fresh muscle; however the data did not reach statistical significance (Fig. 2).

\subsection{Discussion}

The effects of dietary PUFA supplements - mainly linseed, rapeseed or sunflower seed oils, cakes or seeds - on pig performance and fatty acid composition of tissues have been investigated intensively. It is generally known that fat quality of pork can be positively affected by supplementation of animal diets with different oilseeds and oilseed press cakes as well as grass (Wasilewski et al., 2011; Nuernberg et al., 2011; Dan- 
Table 5. Fatty acid profile (\% of the total fatty acids) of longissimus muscle of pigs fed diets supplemented with sea buckthorn pomace.

\begin{tabular}{|c|c|c|c|c|c|c|c|}
\hline Fatty acids (\%) & $\begin{array}{l}\text { CG } \\
\text { LSM }\end{array}$ & $\begin{array}{l}\text { FG1 } \\
\text { LSM }\end{array}$ & $\begin{array}{l}\text { FG2 } \\
\text { LSM }\end{array}$ & $\begin{array}{l}\text { FG3 } \\
\text { LSM }\end{array}$ & $\begin{array}{l}\text { FG4 } \\
\text { LSM }\end{array}$ & $\begin{array}{l}\text { FG5 } \\
\text { LSM }\end{array}$ & SEM \\
\hline$\sum \mathrm{FA}(\mathrm{mg} / 100 \mathrm{~g})$ & 1815 & 1751 & 2079 & 1731 & 1991 & 2193 & 158.9 \\
\hline$\overline{\mathrm{C}} 14: 0$ & 1.3 & 1.3 & 1.3 & 1.3 & 1.4 & 1.4 & 0.04 \\
\hline $\mathrm{C} 14: 1$ & $0.03^{\mathrm{b}}$ & $0.03^{\mathrm{b}}$ & $0.02^{\mathrm{a}}$ & $0.02^{\mathrm{a}}$ & $0.03^{\mathrm{b}}$ & $0.03^{\mathrm{b}}$ & 0.001 \\
\hline $\mathrm{C} 16: 0$ & 24.8 & 25.0 & 24.8 & 24.7 & 25.1 & 25.3 & 0.3 \\
\hline $\mathrm{C} 16: 1$ & 3.6 & 3.7 & 3.7 & 3.6 & 4.0 & 3.8 & 0.1 \\
\hline $\mathrm{C} 18: 0$ & 12.4 & 12.2 & 12.9 & 12.2 & 12.3 & 12.6 & 0.3 \\
\hline C18: 1cis-9 & 36.5 & 36.3 & 37.1 & 35.5 & 36.4 & 37.3 & 0.6 \\
\hline C18:2n-6 & 9.2 & 9.5 & 8.4 & 10.0 & 8.7 & 8.1 & 0.55 \\
\hline $\mathrm{C} 18: 3 n-3$ & $0.39^{\mathrm{a}}$ & $0.47^{\mathrm{b}}$ & $0.41^{\mathrm{ab}}$ & $0.48^{\mathrm{b}}$ & $0.45^{\mathrm{b}}$ & $0.47^{\mathrm{b}}$ & 0.02 \\
\hline $\mathrm{C} 20: 3 n-6$ & $0.35^{\mathrm{a}}$ & $0.36^{\mathrm{a}}$ & $0.30^{\mathrm{b}}$ & $0.36^{\mathrm{a}}$ & $0.32^{\mathrm{b}}$ & $0.30^{\mathrm{b}}$ & 0.03 \\
\hline $\mathrm{C} 20: 4 n-6$ & 2.9 & 3.0 & 2.4 & 3.0 & 2.6 & 2.3 & 0.2 \\
\hline $\mathrm{C} 20: 5 n-3$ & 0.25 & 0.27 & 0.22 & 0.28 & 0.23 & 0.21 & 0.02 \\
\hline $\mathrm{C} 22: 4 n-6$ & 0.35 & 0.35 & 0.29 & 0.35 & 0.30 & 0.27 & 0.03 \\
\hline $\mathrm{C} 22: 5 n-3$ & 0.41 & 0.46 & 0.37 & 0.46 & 0.38 & 0.36 & 0.04 \\
\hline $\mathrm{C} 22: 6 n-3$ & 0.22 & 0.26 & 0.21 & 0.25 & 0.20 & 0.20 & 0.02 \\
\hline $\mathrm{SFA}^{1}$ & 39.8 & 39.1 & 40.5 & 39.5 & 40.0 & 40.5 & 0.4 \\
\hline MUFA $^{2}$ & 45.7 & 45.8 & 46.4 & 44.9 & 46.3 & 46.9 & 0.7 \\
\hline PUFA $^{3}$ & 14.4 & 15.0 & 13.0 & 15.5 & 13.5 & 12.5 & 0.9 \\
\hline$\sum n-3 \mathrm{FA}^{4}$ & 1.4 & 1.5 & 1.3 & 1.5 & 1.3 & 1.3 & 0.09 \\
\hline$\sum n-6 \mathrm{FA}^{5}$ & 13.1 & 13.5 & 11.8 & 14.0 & 12.2 & 11.2 & 0.8 \\
\hline
\end{tabular}

a, b- significant differences between feeding groups at $P \leq 0.05 ; 1$

$\mathrm{SFA}=\mathrm{C} 10: 0+\mathrm{C} 11: 0+\mathrm{C} 12: 0+\mathrm{C} 13: 0+\mathrm{C} 14: 0+\mathrm{C} 15: 0+\mathrm{C} 16: 0+\mathrm{C} 17: 0+\mathrm{C} 18: 0+\mathrm{C} 20: 0+\mathrm{C} 21: 0+\mathrm{C} 22: 0+$ $\mathrm{C} 23: 0+\mathrm{C} 24: 0 ; 2$

MUFA $=\mathrm{C} 14: 1+\mathrm{C} 15: 1+\mathrm{C} 16: 1+\mathrm{C} 17: 1+\mathrm{C} 18: 1 \mathrm{t}+\mathrm{C} 18: 1 \mathrm{c} 9+\mathrm{C} 18: 1 \mathrm{c} 11+\mathrm{C} 22: 1+\mathrm{C} 24: 1 ; 3$

$\mathrm{PUFA}=\Sigma n-3+\Sigma n-6 \mathrm{FA}+c 9, \operatorname{tr} 11 \mathrm{CLA}+\mathrm{C} 18: 2 t ;{ }^{4}$

$\Sigma n-3 \mathrm{FA}=\mathrm{C} 20: 3 n-3+\mathrm{C} 22: 6 n-3+\mathrm{C} 22: 5 n-3+\mathrm{C} 20: 5 n-3+\mathrm{C} 18: 4 n-3+\mathrm{C} 18: 3 n-3 ; 5$

$\Sigma n-6 \mathrm{FA}=\mathrm{C} 22: 2 n-6+\mathrm{C} 20: 2 n-6+\mathrm{C} 18: 3 n-6+\mathrm{C} 22: 4 n-6+\mathrm{C} 20: 3 n-6+\mathrm{C} 18: 2 n-6+\mathrm{C} 20: 4 n-6$

nenberger et al., 2012; Morel et al., 2013; Turner et al., 2014). Until now, the effects of SBP supplementation on growth and meat/fat quality in finishing pig have not been reported apart from in one study by Zhang et al. (2009), in which the effect of early feeding of sea buckthorn extracts on growth performance and meat quality of crossbred Landrace $\times$ Large White pigs was investigated. Zhang et al. (2009) reported a reduced backfat thickness and lower intramuscular fat by early feeding (28th to 57 th day of life) of $0.1 \%$ sea buckthorn extract to pigs. The hypothesis in the present study was that a supplementation with SBP in pig feeding led to positive effects on meat quality and muscle fatty acid profile based on bioactive compounds (e.g. vitamins, flavonoids, ALA) in SBP, and no changes in growth performance and carcass traits were expected. The results of the present study with respect to growth performance and carcass traits confirmed our starting hypothesis. All pigs grew up at the same time during the feeding period. The ADG of pigs was not affected by different SBP contents and feeding durations; however, the ADFI of pigs in FG2 (8\% SBP over 4 weeks) and FG3 ( $8 \%$ SBP over 8 weeks) was significantly higher compared to the control group. The carcass quality (lean meat proportion, backfat thickness, weight of internal organs) was not affected by different SBP supplementation and intervention durations. In total, four different backfat thicknesses were measured; these were not significantly different between intervention groups. In contrast, Zhang et al. (2009) reported a reduced backfat thickness and lower intramuscular fat (IMF) with early feeding (28th to 57 th day of life) of $0.1 \%$ sea buckthorn extract to crossbred pigs. In the present study, the IMF contents of pigs in all groups varied between 1.4 and $1.6 \%$ and did not show significant intervention effects.

However, the results of the present study with respect to meat quality and muscle fatty acid profile/concentrations did not confirm the starting hypothesis and showed only a low number of significant effects of SBP supplementation. The meat quality parameters like $\mathrm{pH}$ value, meat colour and drip loss were not affected by diet. In addition, the macronutrient composition (protein, fat, ash) of longissimus muscle and the meat colour at $45 \mathrm{~min}$ and $24 \mathrm{~h}$ (data not shown) post-mortem were not different between diet groups. SBP supplementation induced changes in the muscle fatty acid profile/concentrations of pigs but to a lower extent than expected. Highest ALA concentrations were found in muscle of pigs fed mixed rations supplemented with $12 \%$ SBP and lowest ALA concentration in the pigs of the control group. This effect is based on higher ALA contents (6-13\%) and a low $n-6 / n-3$ PUFA ratio of $1.1-1.3$ in the lipid fraction of sea 

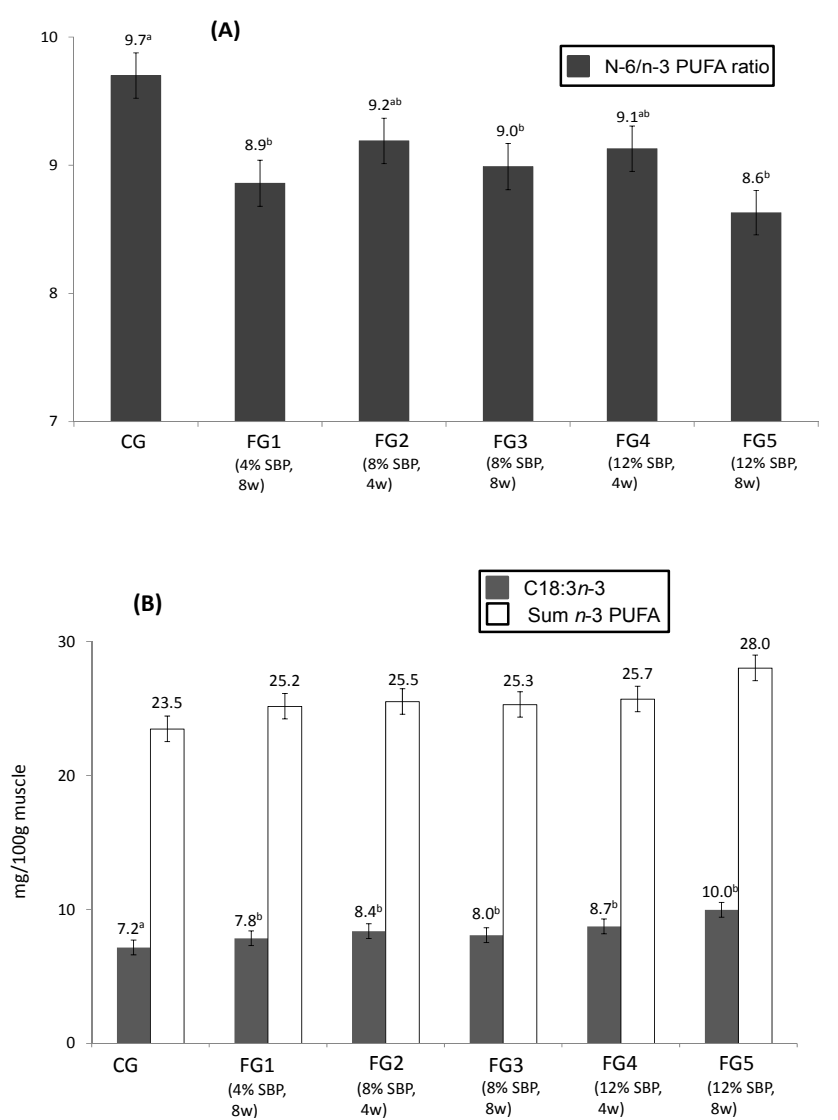

Figure 1. $n-6 / n-3$ PUFA ratio (a), ALA and the sum of $n-3$ fatty acid concentrations $(\mathrm{mg} / 100 \mathrm{~g})$ of longissimus muscle (b) of pigs whose diets were supplemented with sea buckthorn pomace $(\mathrm{LSM} \pm \mathrm{SEM} ; \mathrm{a}, \mathrm{b}-$ significant differences at $P \leq 0.05)$.

buckthorn. However, the extent of accumulation of ALA in muscle fat of pigs fed SBP compared to the control group was lower than initially expected. One reason is likely the low differences in PUFA proportions of the various mixed rations. Although there was a lower $n-6 / n-3$ PUFA ratio in the diets of the SBP feeding groups compared with diet of the control group, the sum of $n-3$ PUFA proportions in the SBP groups were not significantly increased compared with the control group. An 8-week feeding of $12 \%$ SBP (FG5) induced a significant incorporation of ALA into intramuscular fat up to a final concentration of $10.0 \mathrm{mg} / 100 \mathrm{~g}$ muscle, and the sum of $n$-3 PUFA concentrations increased from $23.7 \mathrm{mg} / 100 \mathrm{~g}$ in the control group to $28 \mathrm{mg} / 100 \mathrm{~g}$ muscle $(1.5 \%$ of total fatty acids). In comparison, other studies investigating the effect of supplementation of linseed, rapeseed or sunflower seed oils, cakes or seeds in pigs' diets showed higher accumulation of $n$-3 PUFA in muscle tissues. In muscle of pigs fed with concentrate pellets supplemented with 2.5 or $4 \%$ extruded linseed, the sum $n$-3 PUFA concentrations were enriched up to 3.2 and $4.1 \%$ of total fatty acids compared to $1.7 \%$ sum $n$-3 PUFA in muscle of control-fed pigs (Nuern-

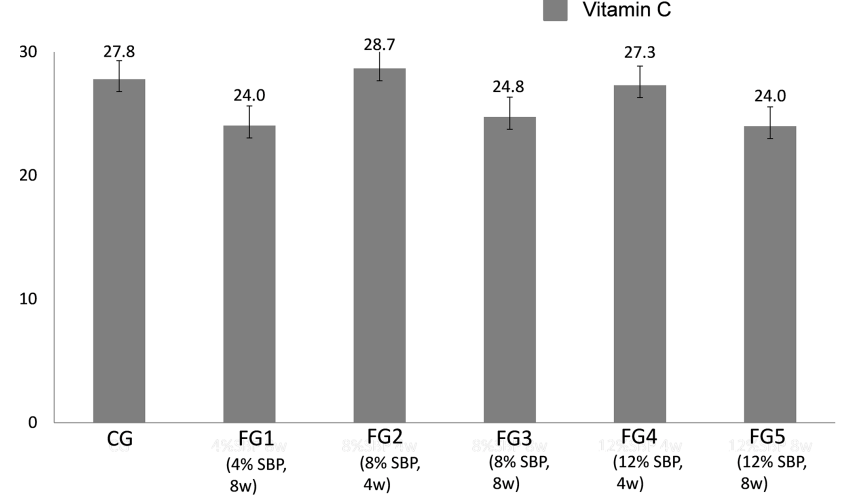

Figure 2. Vitamin C concentrations $\left(\mu \mathrm{g} \mathrm{g}^{-1}\right.$ ) of longissimus muscle of pigs whose diets were supplemented with sea buckthorn pomace $(\mathrm{LSM} \pm \mathrm{SEM})$.

berg et al., 2011). A pig diet supplemented with $6 \%$ extruded linseed led to sum $n$-3 PUFA proportions of $6.9 \%$ in intermuscular tissue of castrated male crossbreeds (Guillevic et al., 2009). Higher $n$-3 PUFA proportions in pig muscle up to $8.8 \%$ of total fatty acids were observed in muscle of pigs fed a blend of linseed/soybean oil supplemented with $4.4 \%$ fish oil (Morel et al., 2013). Although the increase in $n$-3 PUFA in pig muscle of the present study was not as large as in other studies, the $n-6 / n-3$ PUFA ratio of muscle fat of pigs fed SBP-supplemented rations was significantly lower in comparison with the control group, except in FG2 and FG4 (Fig. 1).

Increasing SBP supplementation $(4,8$ or $12 \%$ SBP) induced a decline in the $n-6 / n-3$ PUFA ratio, which was only significant for 12 and $4 \%$ SBP compared with the control group. In order to answer the question of whether the intervention duration or the concentration of SBP has a greater impact, a further variance analysis was performed (excluding the groups CG and FG1); only SBP concentrations of 8 and $12 \%$ over 4 and 8 weeks were compared (data not shown). For the incorporation of ALA into muscle fat, a greater influence of the intervention duration $(P=0.06)$ was found compared to the SBP concentration $(P=0.46)$. The impact of SBP concentration and intervention duration did not differ with respect to the sum of all $n-3$ fatty acids in intramuscular fat (duration, $P=0.18$; concentration, $P=0.89$ ), whereas intervention duration $(P=0.05)$ exhibited a greater effect on the $n-6 / n-3$ PUFA ratio than SBP concentration $(P=0.20)$ (data not shown). In the case of MUFAs, both the relative proportion and the concentration of main MUFAs in pig muscle, C18:1cis-9 and C16:1cis9, in the SBPsupplemented groups were not significantly higher compared with the control group, although a slight increase in these MUFAs with increasing SBP supplementation was detected. Besides the effect on the fatty acid profile, it is well known that sea buckthorn has excellent antioxidant properties due to high amounts of bioactive substances (Korekar et al., 2011). 
The results of the present study showed that neither the concentration of SBP nor the duration of supplementation affected the muscle vitamin $\mathrm{C}$ concentrations. One explanation could be a higher consumption of vitamin $\mathrm{C}$ for antioxidant defence in supplemented SBP groups which led to unaffected vitamin $\mathrm{C}$ contents in the muscle of SBP-supplemented pigs.

In conclusion, the use of SBP as a supplement in pig diets did not lead to the expected changes predominantly in the fatty acid profile and vitamin concentrations in pig muscle. In further studies, diet composition and possibly changes in SBP during the manufacturing process of diet pellets should be included in investigations in order to develop an application-oriented concept of SBP as a supplement for pig feeding.

Acknowledgements. We gratefully acknowledge M. Dahm and B. Jentz for the excellent chemical analyses and M. Zenk and the staff of the pig facility for animal feeding and keeping.

Edited by: K. Wimmers

Reviewed by: two anonymous referees

\section{References}

Baum, S. J., Kris-Etherton, P. M., Willett, W. C., Lichtenstein, A. H., Rudel, L. L., Maki, K. C., Whelan, J., Ramsden, C. E., and Block, R. C.: Fatty acids in cardiovascular health and disease: a comprehensive update, J. Clin. Lipidol., 6, 216-234, 2012.

Cossuta, D., Simándi, B., Hohmann, J., Doleschall, F., and Keve, T.: Supercritical carbon dioxide extraction of sea buckthorn (Hippophae rhamnoides L.) pomace, J. Sci. Food. Agr., 87, 24722481, 2007.

Dannenberger, D., Nuernberg, K., Nuernberg, G., and Priepke, A.: Different dietary protein and PUFA interventions alter the fatty acid concentrations, but not the meat quality, of porcine muscle, Nutrients, 4, 1237-1246, 2012.

Guillevic, M., Kouba, M., and Mourot, J.: Effect of a linseed or sunflower diet on performances, fatty acid composition, lipogenic enzyme activities and stearoyl-CoA-desaturase activity in the pig, Livest. Sci., 124, 288-294, 2009.

Hornig, R. and Hoehne, F.: Sanddorn-Alternative und Perspektive für den Erwerbsanbau?, Obstbau, 36, 508-513, 2011.

Kagliwal, L. D., Pol, A. S., Patil, S. C., Singhal, R. S., and Patravale, V. B.: Antioxidant-rich extract from dehydrated sea buckthorn berries by supercritical carbon dioxide extraction, Food Bioprocess. Tech., 5, 2768-2776, 2012.
Korekar, G., Stobdan, T., Singh, H., Chaurasia, O. P., and Singh, S. B.: Phenolic content and antioxidant capacity of various solvent extracts from sea buckthorn (Hippophae rhamnoides L.) fruit pulp, seeds, leaves and stem bark, Acta Aliment Hung, 40, 449458, 2011.

Lopez, S., Bermudez, B., Varela, L. M., Ortega, A., Jaramillo, S., Abia, R., and Muriana, F. J. G.: Olives and olive oil: diet and health impact, CAB reviews, 7, 1-7, 2012.

Miura, K., Stamler, J., Brown, I. J., Ueshima, H., Nakagawa, H., Sakurai, M., Chan, Q., Appel, L. J., Okayama, A., Okuda, N., Curb, J. D., Rodriguez, B. L., Robertson, C., Zhao, L., and Elliott, P.: Relationship of dietary monounsaturated fatty acids to blood pressure: the international study of macro/micronutrients and blood pressure, J. Hypertens., 31, 1144-1150, 2013.

Morel, P. C., Leong, H., Nuijten, J., Purchas, R. W., and Wilkinson, B. H. P.: Effect of lipid type on growth performance, meat quality and the content of long chain n-3 fatty acids in pork meat, Meat Sci., 95, 151-159, 2013.

Nuernberg, K., Wegner, J., and Ender, K.: Factors influencing fat composition in muscle and adipose tissue of farm animals, Livest. Sci., 56, 145-156, 1998.

Nuernberg, K., Nuernberg, G., Dannenberger, D., Hagemann, L., and Paulke, T.: Wirkung von extrudierter Leinsaat in der Schweinemast, Fleischwirtschaft, 91, 88-92, 2011.

Pfeuffer, M.: Physiologic effects of individual fatty acids in animal and human body, with particular attention to coronary heart disease risk modulation, Arch. Tierz., 44, 89-98, 2001.

Prabhu, R. A., Prasad, G. A., Manivannan, J., Elavarasan, S., and Balaji, S.: Review on curative assets of sea buckthorn, Pharmacol. Res., 4, 164-166, 2011.

SAS Institute Inc.: SAS/STAT ${ }^{\circledR} 9.4$ User's Guide. Cary, NC: SAS Institute Inc., 2012.

Shen, X., Dannenberger, D., Nuernberg, K., Nuernberg, G., and Zhao, R.: Trans- 18:1 and CLA isomers in rumen and duodenal digesta of bulls fed n-3 and n-6 PUFA-based diets, Lipids, 46, 831-841, 2011.

Turner, T. D., Mapiye, C., Aalhus, J. L., Beaulieu, A. D., Patience, J. F., Zijlstra, R. T., and Dugan, M. E. R.: Flaxseed fed pork: n-3 fatty acid enrichment and contribution to dietary recommendations, Meat Sci., 96, 541-547, 2014.

Vaclavkova, E. and Beckova, R.: Effect of linseed in pig diet on meat quality and fatty acid content, Arch. Tierz., 50, Special Issue, 144-151, 2007.

Wasilewski, P. D., Nowachowicz, J., Michalska, G., Bucek, T., Lynch, B., and Mullen, A. M.: Fatty acid profile of Longissimus dorsi muscle of crossbred pigs fed with addition of conjugated linolic acid or sunflower oil, Arch. Tierz., 54, 61-68, 2011.

Zhang, Z., Xia, L. L., Chen, X., Zhao, W., Wang, P., Su, J., and Li, Y.: Effects of early feeding sea buckthorn extracts on growth performance, meat quality, serum leptin levels and leptin mRNA expression of adipose tissue in swine. Chinese, J. Anim. Nutr., 21, 734-740, 2009. 